the urinary excretions. It may also be argued that when fortified white bread is used in the diet there may be insufficient vitamin E. In spite of the paper by Moore, Sharman \& Ward (I957), there is no evidence for this belief. In baking, 50\% of the vitamin $\mathrm{E}$ in the flour is destroyed and cereals do not contribute much vitamin $\mathrm{E}$ to the diet (see Frazer, Hickman, Sammons \& Sharratt, 1956). We indeed know little of the daily requirements of vitamin $\mathrm{E}$.

If we are to take a broad and fair view after examination of all the established facts, I find it extremely difficult to believe, as I have always done, that there is any valid criticism of the procedure of pleasing the public by giving them the white flour they desire, provided that fortification as we understand it today is properly carried out. There is quite frankly no evidence that a normal diet containing bread made from enriched flour lacks any essential nutrient as opposed to a similar diet in which the bread is made from flour of longer extraction, for example $80-85 \%$. The evidence is that the diet will not be lacking in the rarer components of the $B$ group of vitamins such as pantothenic acid, pyridoxine, folic acid or biotin. The fact remains that no evidence of malnutrition has been shown in all the many carefully conducted tests so far made.

\title{
REFERENCES
}

Frazer, A. C., Hickman, J. R., Sammons, H. G. \& Sharratt, M. (1956). F. Sci. Fd Agric. 7, 375. Great Britain. Parliament (1945). Report of the Conference on the Post-War Loaf. [Cmd.6701]. London: H.M. Stationery Office.

Great Britain. Parliament (1956). Report of the Panel on Compasition and Nutritive Value of Flour [Cmd. 9757]. London: H.M. Stationery Office.

Kent-Jones, D. W. (1946). Proc. Nutr. Soc. 4, I4.

Kent-Jones, D. W. (1949-50). F. R. Soc. Arts, 98, ז 50.

McCance, R. A. \& Widdowson, E. M. (1956). Breads White and Brown. London: Pitman Medical Publishing Co. Ltd.

Moore, T., Sharman, I. M. \& Ward, R. J. (1957). F. Sci. Fd Agric. 8, 97.

Widdowson, E. M. \& McCance, R. A. (1954). Spec. Rep. Ser. med. Res. Coun., Lond., no. 287.

Wilder, R. M. (1949). Canad. med. Ass. F. 60, 329.

Wilder, R. M. (1956). F. Amer, med. Ass. r62, I539.

\section{Analytical problems in the determination and control of extraction rates of flour}

By J. R. Nicholls and J. R. Fraser, Department of the Government Chemist, Government Laboratory, Clement's Inn Passage, Strand, London, W.C.2

Extraction rate is a term used to define the grade of a flour and is expressed as a percentage showing the relation of the weight of flour to the weight of wheat from which it is obtained. It is inherent in the term that it applies only to flour produced and not to any other product separated from wheat. Flour is, however, a generic term covering a wide variety of products and it must be interpreted, for the purposes of definition of extraction rate, as the product which the miller sets out to prepare 
from wheat by removing the by-products that he does not wish to incorporate in his flour.

In the early days of milling, wheat was ground and sieved to separate the flour from the by-products and, according to the extent of these two operations, the grade of the flour varied. In such circumstances it was an easy matter to express the weight of flour extracted as a percentage of that of the wheat operated upon. The miller was a business man and his object was to obtain the maximum amount of flour of the desired grade with a consequent minimum of by-products.

The wheat grain consists essentially of three parts, (I) the small germ or embryo situated at one end of the grain and enclosed within a thin sheath, the scutellum; (2) the starchy endosperm comprising the body of the grain; and (3) the outer covering of bran consisting of a number of layers of varying degrees of toughness and adherence. The proportions of these three parts are approximately: $2 \%$ of germ, $85 \%$ of endosperm, $13 \%$ of bran. Flour consists of the ground endosperm together with such amounts of the ground germ and bran as accompany the ground endosperm by the milling operation employed.

Until about $\mathrm{I} 880$ milling was performed by grinding between stones, one of which was rotated. The motive force in the early days was man, but subsequently cattle, the wind and steam were employed. It was recognized that such an operation was inefficient because the three main parts of the grain varied considerably in toughness and the maximum of endosperm could not be obtained as flour except by the inclusion of considerable amounts of comminuted bran.

Soon after $\mathrm{i} 880$ milling was revolutionized by the introduction of the roller mill and cleaning system, and from a simple mechanical operation became an art. The principle of the change was to replace the grinding of the wheat as a whole by operations which broke the grains, sheared off the tougher bran coatings, and cracked the endosperm into coarse particles called semolina, and then in a suitable sieving and purification plant to separate the bran and to grade the semolina according to size and purity. According to the type of wheat dealt with, the miller used his art and skill to arrange a series of break rollers with sieves between each set so that semolina, purified to an appropriate extent, could be obtained, which by subsequent grinding and dressing yielded the grade of flour desired. Modern millers adopt the same general technique and, because of the variety of streams which come from different parts of the plant, the by-products can be graded as well as the flour. As already stated, extraction rate can be applied only to the flour.

In a 'straight-run' process the whole of the flour streams are collected together so that it is easy to specify the extraction rate. But in many mills the flour streams are kept separate and any one may be further separated into tops and bottoms, called 'divides'. By these means the purest and whitest flour, consisting almost entirely of pure endosperm and called 'patents' can be as it were skimmed from the mill products. The rest of the flour (the bottoms) will simulate a flour of straightrun milling of an extraction rate much higher than that which the mill was set to produce, when calculated from the total flour made relative to the amount of grist 
used. Any bottom flour produced from 'divides' may therefore be said to correspond to a straight-run flour of a particular extraction rate.

Because of the complicated series of operations performed and the variations that may occur in different mills, even straight-run flour of a particular extraction may not always be of the same composition. Larger differences are to be expected in flour produced by blending 'divides'.

It is thus evident that the extraction rate is not an absolute parameter for defining the grade of a flour. It being so it might be argued that the term should be discarded. On the other hand, if it serves a useful purpose, account must be taken of its limitations. Within the milling industry the term is widely used and appears to be generally understood. The analyst, has the problem, therefore, of attempting to determine it, or rather of satisfying himself that any stated extraction rate has been applied appropriately.

Millers base a statement of extraction rate either on their milling records or on the appearance of a sample. Appearance is not synonymous with colour but depends more on a combination of colour and brightness, which is modified by granularity and the make-up of the flour. Personal judgment integrates all the factors in a way in which no single objective measurement can. A commonly applied test is the Pekar. Flour is placed on a board, pressed with a smooth surface and the edges of the slab trimmed. Other flours for comparison are treated similarly on the same board, the edges touching. The whole is dipped into water and allowed to dry slowly. Comparisons are made before dipping, immediately after dipping and an hour or so later when dry. Though millers are expert in their judgment and interpretation, the test is of limited value to the analyst, unless he is fully informed as to the grist and the milling technique used.

The practical range of extraction rates with which the analyst is concerned is from wholemeal flour of $100 \%$ extraction to white flour of about $70 \%$ extraction. Flours of lower extraction are called patents and whether the rate of these is 40,50 or $60 \%$ is of no real significance. Flour of $100 \%$ extraction contains the whole of the wheat, including all its husk or bran; flour of $70 \%$ extraction, which comprises the maximum amount of the whitest flour that can be produced, contains only that amount of bran that has unavoidably passed with the endosperm through the purifiers. Between these limits the amount of bran gradually decreases. Moran \& Drummond (1945) give the proportions of bran, germ and endosperm in flours of different extractions:

\begin{tabular}{lcrcr} 
& \multicolumn{4}{c}{ Rate of extraction of flour } \\
Fraction & $100 \%$ & $85 \%$ & $82 \frac{1}{2} \%$ & $80 \%$ \\
Bran & 12 & 3.4 & $2 \cdot 0$ & $1 \cdot 4$ \\
Germ & $2 \cdot 5$ & $1 \cdot 9$ & $1 \cdot 7$ & $1 \cdot 6$ \\
Endosperm & 85.5 & $79 \cdot 7$ & $78 \cdot 8$ & $77 \cdot 0$ \\
Total & 100 & $85 \cdot 0$ & 82.5 & 80.0
\end{tabular}


Expressed as percentages of the flour these become:

\begin{tabular}{lcrcr} 
& \multicolumn{4}{c}{ Rate of extraction of flour } \\
Fraction & $100 \%$ & $85 \%$ & $82 \frac{1}{2} \%$ & $80 \%$ \\
Bran & 12 & $4 \cdot 0$ & $2 \cdot 4$ & $1 \cdot 8$ \\
Germ & $2 \cdot 5$ & $2 \cdot 2$ & $2 \cdot 1$ & $2 \cdot 0$ \\
Endosperm & $85 \cdot 5$ & 93.8 & $95 \cdot 5$ & $96 \cdot 0$ \\
Total & $100 \cdot 0$ & $100 \cdot 0$ & $100 \cdot 0$ & $100 \cdot 0$
\end{tabular}

In considering these tables the analyst has to bear the following facts in mind:

Bran: whereas $100 \%$ extraction flour contains the whole of the bran, lowerextraction flours contain only selected fractions of the bran layers, which may have different compositions from that of the whole bran.

Germ: some mills set out to separate the germ as such. In practice about onehalf can be removed, the remainder being inseparable from the flour stream.

Endosperm: it can be regarded as of substantially the same composition whatever the extraction rate.

Flours of different extraction rates have different nutritive values. The total calories are much the same and there is no substantial difference in the main constituents of protein, fat and total carbohydrates. It is in the proportions of the vitamins of the B group that the main differences occur. These accessory food factors are associated with the bran and with the germ (particularly its scutellum). The whitest flour contains the minimum of vitamins, and 100\% extraction flour contains all that the grain possessed. Flours of intermediate extraction rates contain variable proportions of the vitamins of the wheat; but because of the differences in milling techniques there is only a very rough parallelism between extraction rates and proportion of vitamins. Such correlation as exists is upset by the national policy of the addition of 'token nutrients', i.e. selected members of the B group. However, vitamins not at present affected by fortification in this country might still be considered as indicators of the grade of a flour. Of these biotin appears to offer the most useful range of values as one proceeds from 'low-extraction' flours to brown and wholemeal.

A second method for assessing the grade of a sample of flour by analysis is the general appearance. Reference has already been made to the Pekar test but skill and experience are required to carry it out properly. We have now means to supplement (if not supplant) this test by use of a reflectance spectrophotometer specially designed for wheat-flour work by Kent-Jones \& Martin (1950) and Kent-Jones, Amos \& Martin (1950). It gives a numerical assessment of colour, on an arbitrary scale, which these authors have shown to be strongly related to the natural ash content, and therefore is similarly indicative of the inclusion of a high or low proportion of non-endosperm in the flour.

The use of the ash itself for grading may be obscured by added materials such as chalk. This added matter must be determined and allowed for, or alternatively attention must be focussed on a natural ash constituent (such as the phosphate, $\mathrm{P}_{2} \mathrm{O}_{5}$ ) which would be unaffected by the substance added. The amount of natural 
mineral matter taken as a total (i.e. ash) or as a single constituent will accord with the proportion of non-endosperm.

From what has already been said, it is evident that the classification of modern flours according to their extraction rates is very imprecise from the standpoint of determinable properties. The best that can be done is to find such analytical parameters as are typical of the majority of flour samples produced from normal grist mixtures over a period of time by as many commercial mills as possible, and to record these values together with the coefficient of variation found for each. When sufficient consistent data have beeen accumulated, it becomes possible to judge whether an unknown sample of an alleged extraction rate is reasonably within the limits of credibility for such a claim. These data do not exist for all possible extraction rates. Even the numerous figures relating to National flour during the war and postwar periods are not strictly applicable for this purpose as the flours then produced were invariably mixed with varying amounts of imported flour. They nevertheless indicate the kind of assessment which would be possible should there be an obligatory type of flour to be produced.

Further, it is of advantage to consider not only each individual parameter that can be numerically assessed but two or more together in a different number of ways. This operation can be done by a variation of Fisher's discriminant function as described by Steiner (I949), and involves calculation of an artificial value, known as the optimum combination (O.C.), the coefficient of variation of which is less than that of any of its components. The degree to which the O.C. can be reduced is dependent on the correlation existing between the components.

It now remains to consider what parameters are suitable for such analysis. As already indicated, the main variable between $70 \%$ and $100 \%$ extraction flour is the proportion of bran. The following table shows the approximate general compositions of endosperm and bran, calculated to a moisture-free basis:

\begin{tabular}{|c|c|c|}
\hline Constituent & $\begin{array}{c}\text { Endosperm } \\
(\%)\end{array}$ & $\begin{array}{c}\text { Bran } \\
(\%)\end{array}$ \\
\hline Protein & I I-I4 & $33^{-16}$ \\
\hline & Up to 1 & $3^{-5}$ \\
\hline Ash & Up to 0.5 & $5-6$ \\
\hline $\begin{array}{l}\text { Carbohydrates by difference } \\
\text { including fibre }\end{array}$ & $\begin{array}{l}\text { c. } 86 \\
\text { Up to } 0.25\end{array}$ & $\begin{array}{l}\text { c. } 74 \\
10-12\end{array}$ \\
\hline
\end{tabular}

In flours of different extraction rates, the endosperm is of substantially the same composition; but in the lower-extraction flours the bran present is not whole bran. The difference in adherence and tenacity of the various layers of bran results in partition and, as the fat, ash and fibre of the layers are different, these parameters have limited value as measures of the amount of bran. No information is available that any differences in the proteins of the endosperm and bran can be used for discrimination.

This brings us finally to a consideration of the carbohydrates. For a long time the 'fibre' figure was favoured as an index of flour grade. It certainly has its practical uses. It is, however, essentially an artificial value - the result of an empirical drill 
-and does not represent a 'quantity' of any particular constituent present, in spite of its being sometimes referred to loosely as 'cellulose'.

When, however, one comes to flours below a certain grade, the fibre figure becomes too small for reliability in differentiating between flours from different sources. Both the ash and colour-grade value can be determined with much greater precision, ease and time-saving, and their information is more to the point.

The carbohydrate fraction of a wheat flour is composed generally of: (I) starch, (2) sugars (including soluble polysaccharides which yield hexoses on hydrolysis), (3) hemicelluloses (including furfural-yielding substances), (4) cellulosic material. Methods have been published for the estimation of these components (Fraser, Brandon-Bravo \& Holmes, 1956).

The endosperm carbohydrates include: (I) starch, (2) sugars, (3) furfurogenic matter, (4) small amount of cellulose.

The non-endosperm carbohydrates include: (I) sugars, (2) furfurogenic material, (3) cellulosic material. The starch is provided almost entirely by the endosperm. If therefore we take as an index of grade of flour the ratio of non-starch carbohydrates to starch, we get a value which rises very steeply according to the amount of nonendosperm matter included in the final product. Flours can, however, be variable according to the grist used. One of the main differences is in the protein content, which is appreciably less in the weak wheats (e.g. English) than in strong wheats (e.g. Manitoba). Flours of the same extraction rate might easily differ by $2 \%$ in their protein contents. The carbohydrate by difference of a low-protein flour must be greater than that of a similar high-protein flour. This means that we must expect more or less starch in a flour according to whether there is less or more protein.

Table I. Table of indices of grade for wheat flours

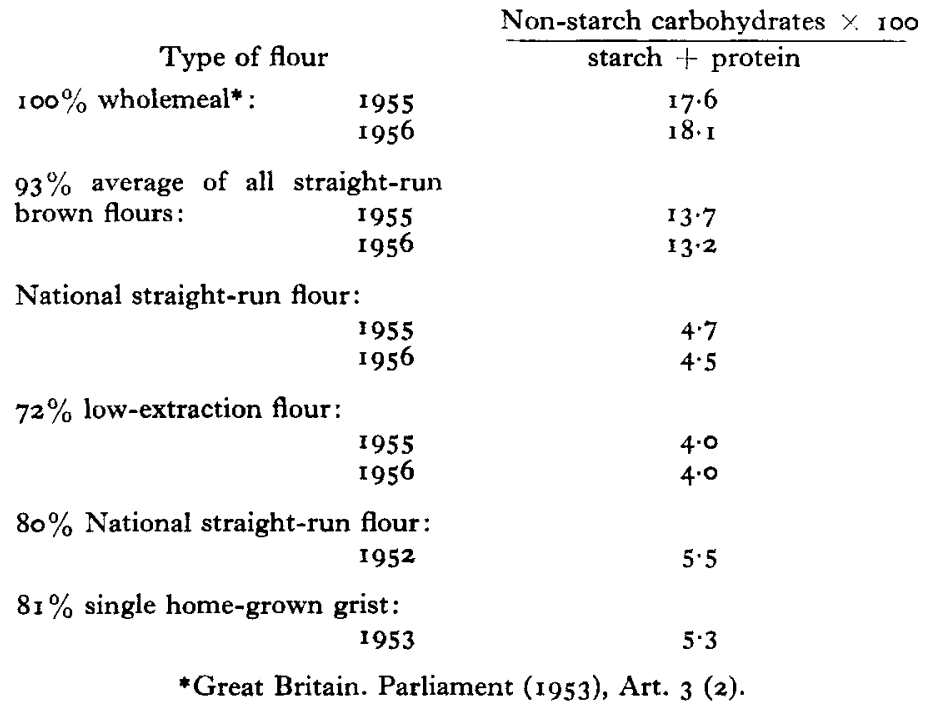


It is therefore suggested that one should take a combination of starch + protein as a reference value, which will have a smaller degree of variation for any one grade of flour than that of starch itself. The index of grade of flour thus becomes:

$$
\frac{\text { Non-starch carbohydrates } \times 100}{\text { starch }+ \text { protein }}
$$

This index (Table $\mathrm{I}$ ) then provides a basis for the comparison of different grades of flour irrespective of the grists from which they were made.

Considerations of all these data therefore may lead one to express an opinion as to the approximate extraction rate at which a flour was milled, but no set of operations or calculations can be advocated that can claim to determine the extraction rate by means of analysis. Each flour must be examined on its individual merits and assessed according to all the clues afforded by its history and composition.

\section{REFERENCES}

Fraser, J. R., Brandon-Bravo, M. \& Holmes, D. C. (1956). F. Sci. Fd Agric. 7, 577. Great Britain. Parliament (1953). The Flour Order, 1953. Stat. Instrum. no. I 282.

Kent-Jones, D. W., Amos, A. J. \& Martin, W. (1950). Analyst, 75, 133.

Kent-Jones, D. W. \& Martin, W. (1950). Analyst, 75, 127.

Moran, T. \& Drummond, J. (1945). Lancet, 248, 698.

Steiner, E. H. (1949). Analyst, 74, 429. 